\title{
Effects of ACTH, Dexamethasone, Adrenalectomy and Stress on cAMP Content of Adenohypophysis and Adrenals in Rats
}

\author{
HideICHI MAKINO, MichiKo MASAKA, YASUHISA MATSUSHIMA, \\ AzUMA KANATSUKA, MASAHIRO YAMAMOTO, \\ AND AKIRA KUMAGAI \\ The Second Department of Internal Medicine, \\ Chiba University School of Medicine, Chiba City, Chiba 280
}

\section{Synopsis}

The effects of adrenalectomy, ether-laparotomy stress and in vivo administration of either ACTH or dexamethasone on the cAMP levels in the anterior pituitary and the adrenal glands were investigated in male rats. After adrenalectomy or etherlaparotomy stress, an increase of the pituitary cAMP levels was observed. A prior administration of dexamethasone failed to inhibit the increase of the pituitary cAMP levels. Acute administration of dexamethasone increased the cAMP levels in the pituitary. Chronic administration of dexamethasone decreased the cAMP levels in the pituitary, but ACTH did not. These data suggest that cAMP might be involved in the mediation of the hypothalamo-pituitary-adrenal axis.

The role of adenosine-3', 5'-monophosphate (cAMP) as a second messenger in hormonal action has been demonstrated in a variety of endocrine systems. Recent evidences also suggest that changes in pituitary adenyl cyclase system may be closely associated with the release of hormones from the gland (Schofield, 1967; Wilber et al., 1968; Zor et al., 1969; Bowers, 1970). It was observed an increase in pituitary ACTH release in vitro in response to theophylline or dibutyryl analog of cAMP (Fleisher et al., 1969). It was also shown that the intrapituitary administrations of dibutyryl analog of cAMP or of theophylline increased ACTH release in vivo (Hedge, 1971). Very recently it was shown that the content of cAMP in hypothalamus and adenohypophysis changed according to the type of stress imposed in vivo (Siegel et al., 1974). The present study was initiated to investigate changes

$\overline{\text { Received for publication January 7, }} 1975$. in cAMP contents in both pituitary and adrenal glands in the rat under various conditions known to alter the function of hypothalamo-pituitary-adrenal axis.

\section{Materials and Methods}

Male rats of Sprague-Dawley strain weighing 150$200 \mathrm{~g}$ were used in the present study. The animals were maintained at $24^{\circ} \mathrm{C}$ with controlled lighting (lights on 05:00-19:00) and given free access to laboratory chow purchased from Oriental Yeast Co., Tokyo and tap water throughout the experiment. Both synthetic $\alpha^{1-24}$ ACTH and $\alpha^{1-24}$ ACTH-Zn were purchased from Daiichi Chemical Co., Tokyo and ${ }^{3} \mathrm{H}$-cAMP (specific activity $22.1 \mathrm{Ci} / \mathrm{m}$ mole) was obtained from New England Nuclear Corp.. Dexamethasone phosphate was obtained from Banyu Pharmaceutical Co., Tokyo.

Acute administration of ACTH and of dexamethasone

The animals were divided into three groups consisting of 6 animals each. They were given either $50 \mu \mathrm{g}$ of $\alpha^{1-24} \mathrm{ACTH}, 100 \mu \mathrm{g}$ of dexamethasone phosphate, or physiological saline solution intravenously. The drugs were dissolved in physiological saline 
solution to make required concentrations in $0.1 \mathrm{ml}$ of the solution and were given to the animals through the tail vein. These animals were sacrificed by decapitation 15 minutes after the injection and their anterior pituitaries and adrenal glands were subjected to cAMP determination.

\section{Chronic administration of ACTH and of dexa- methasone}

Physiological saline solution $0.1 \mathrm{ml}$, either containing $50 \mu \mathrm{g}$ of $\alpha^{1-24} \mathrm{ACTH}-\mathrm{Zn}, 100 \mu \mathrm{g}$ of dexamethasone phosphate, or saline alone was administered daily to the animals intramuscularly for 3 or 7 successive days. The animals were killed by decapitation 24 hours after the last injection and cAMP contents in both adrenals and pituitary glands were determined.

\section{Bilateral adrenalectomy}

Six animals were subjected to the bilateral adrenalectomy under Nembutal anesthesia and given physiological saline solution ad libitum. The rats were decapitated 7 days after the operation and their anterior pituitary glands were served for the cAMP study.

\section{Stress by ether inhalation plus laparotomy}

Six animals were placed to inhalate ether vapor for one minute, followed immediately by laparotomy. They were killed by dacapitation 10 minutes after the ether exposure and either cAMP levels of both pituitary and adrenal glands or plasma 11-OHCS was determined. Same number of animals which had been given $100 \mu \mathrm{g}$ of dexamethasone intramuscularly 3 hours prior to the exposure to stress were treated in the same manner.

\section{Determination of tissue cAMP and plasma corticosterone}

All animals were sacrificed by decapitation in the morning between $9: 00$ to $12: 00$. The anterior pituitary glands and the adrenals were quickly removed, freed from blood and other tissues, weighed, and homogenized in ice cold bath by the teflon Potter-type homogenizer containing 5\% TCA solution within two minutes after the decapitation. The homogenates were centrifuged under refregeration at $3,000 \mathrm{~g}$ for 15 minutes. The supernatants thus prepared were subjected to extraction with cold ether and the extracts were kept frozen until the cAMP assay. cAMP contents were determined by the competitive protein binding assay (Oka et al., 1973) using the binding protein prepared from rat liver (Kumon et al., 1970). Each triplicates of the samples as well as cAMP standards was assayed in duplicates. The quantity of ${ }^{3} \mathrm{H}$-cAMP used was $0.4 \mathrm{p}$ mole $/ 50 \mu l$, and radioactivity of ${ }^{3} \mathrm{H}$-cAMP was determined by Packard liquid scintillation counter (Model 3320) with a scintillation fluid containing $0.1 \mathrm{~g}$ of 1 , 4-bis-2- (4 methyl-6-phenyloxazole) benzene and $5.5 \mathrm{~g}$ of 2 , 5diphenyloxazole in $1,000 \mathrm{~m} l$ toluen and triton $\mathrm{X}-100$, $(2: 1, v / v)$ and quenching was corrected using the external standard. The method employed to estimate cAMP was sensitive to determine $0.25 \mathrm{p}$ mole/tube and assured that neither ATP up to $2.5 \mathrm{n}$ mole/tube nor cGMP up to $50 \mathrm{p}$ mole/tube caused any competition with cAMP. Plasma corticosterone was. determined by the acid fluorescine method (DeMoor et al., 1960). Statistical comparison between groups. was carried out using Student's $t$-test.

\section{Results}

The effect of acute administration of $A C T H$ or dexamethasone on the cAMP concentration

There were no differences in the weights. of adrenal and pituitary glands among control and treated animals. Dexamethasone $(100 \mu \mathrm{g})$ caused an significant increase in the cAMP concentration in the pituitary gland $(\mathrm{p}<0.001)$ (Fig. 1) but not in the adrenal gland (Table 1). On the contrary, ACTH $(50 \mu \mathrm{g})$ had no effect on the pituitary cAMP concentration (Fig. 1), while causing a marked increase in the adrenal cAMP concentration $(\mathrm{p}<0.001)$ (Table 1$)$.

The effect of chronic administration of $A C T H$ or dexamethasone on the CAMP concentration in the pituitary and the adrenal glands.

Administration of ACTH increased significantly the adrenal weight, while dexamethasone decreased it significantly. However, both drugs exerted no effect on the pituitary weight. ACTH administration for either 3 or 7 days brought about significant increases in the cAMP contents ( $\mathrm{p}$ mole/ gland) in the adrenals (Table 1). However, cAMP in both pituitary and adrenal glands, once expressed on the basis of per $\mathrm{mg}$ of wet tissue, did not significantly differ from the control animals ( $\mathrm{p}>0.05)$ (Fig. 2, 3). On the other hand, dexamethasone signifi- 
cantly decreased the cAMP contents in both adrenal and pituitary glands irrespective of duration of the treatment (Fig. 2, 3, Table 1).

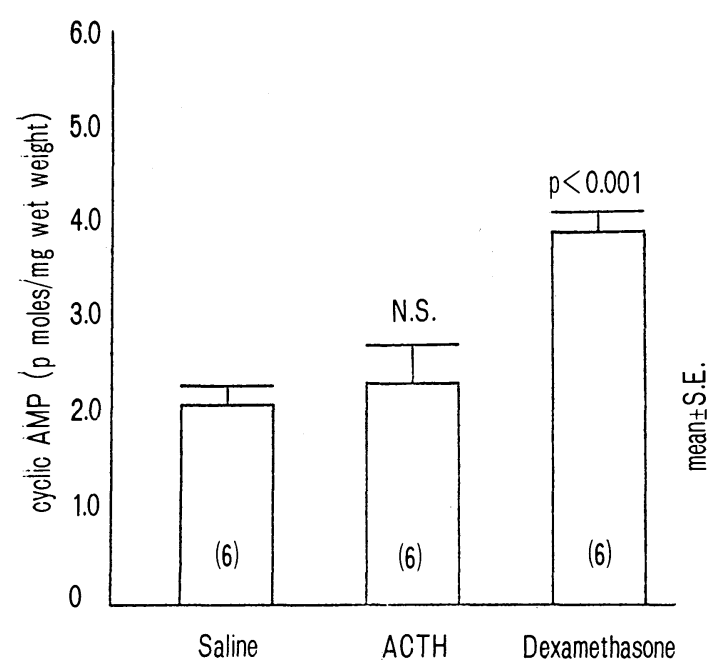

Fig. 1. Effect of a single administration of ACTH or dexamethasone on rat anterior pituitary cAMP. The male rats were given either $50 \mu \mathrm{g}$ of $\alpha^{1-24}$ $\mathrm{ACTH}, 100 \mu \mathrm{g}$ of dexamethasone phosphate, or physiological saline solution intravenously $15 \mathrm{~min}$. prior to the sacrifice. cAMP levels are expressed as $\mathrm{p}$ moles/mg wet weight. Standard errors are given by vertical lines. The figures in brackets refer to numbers of glands assayed in each experiment.

Table 1. Effect of in vivo administration of $\mathrm{ACTH}$, dexamethasone, and ether-laparotomy stress on cAMP content in adrenal glands.

\begin{tabular}{llll}
\hline \hline & & $\begin{array}{c}\text { cAMP concen } \\
\text { tration in adrenals }\end{array}$ & $\begin{array}{c}\text { cAMP content } \\
\text { per gland }\end{array}$ \\
\cline { 3 - 4 } & & $\begin{array}{l}\text { p mole/mg } \\
\text { wet weight }\end{array}$ & p mole \\
\hline 15 min & Saline & $1.0 \pm 0.3 *$ & \\
& ACTH & $11.1 \pm 1.0 \mathrm{p}<0.001$ \\
& Dex. & $0.9 \pm 0.1 \mathrm{~N} . \mathrm{S}$. \\
\hline 3 days & Saline & $3.0 \pm 0.2$ & $72 \pm 5$ \\
& ACTH & $2.8 \pm 0.4 \mathrm{~N} . \mathrm{S}$. & $125 \pm 15 \mathrm{p}<0.01$ \\
& Dex. & $2.1 \pm 0.04 \mathrm{p}<0.01$ & $32 \pm 2 \mathrm{p}<0.001$ \\
\hline 7 days & Saline & $2.7 \pm 0.2$ & $75 \pm 15$ \\
& ACTH & $2.5 \pm 0.3 \mathrm{~N} . \mathrm{S}$. & $169 \pm 28 \mathrm{p}<0.02$ \\
& Dex. & $1.9 \pm 0.2 \dot{\mathrm{p}}<0.05$ & $21 \pm 3 \mathrm{p}<0.01$ \\
\hline Ether- & Control & $1.4 \pm 0.1$ & \\
laparotomy & Stress & $3.5 \pm 0.3 \mathrm{p}<0.001$ & \\
stress & & & \\
\hline
\end{tabular}

* mean \pm S.E.

Treatments were done by the same procedures as in Figs. 1, 2, 3 and 4.

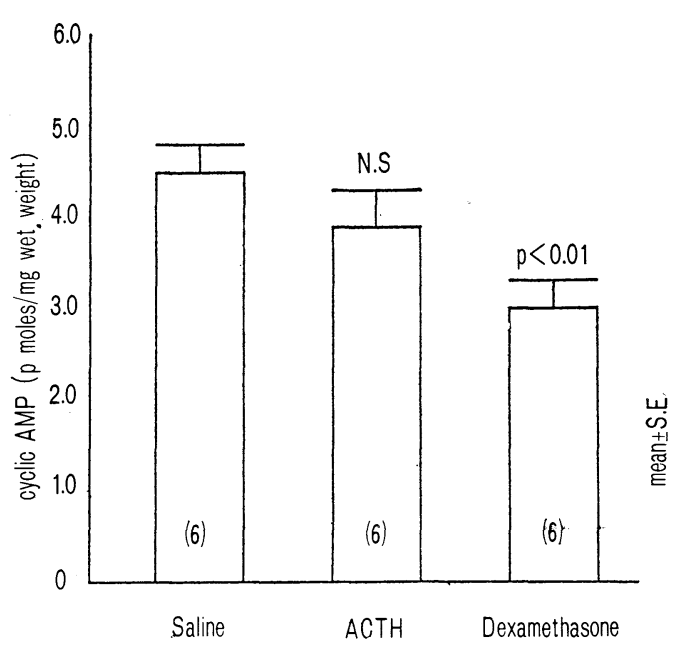

Fig. 2. Effect of 3 days administration of ACTH$\mathrm{Zn}$ or dexamethasone on rat anterior pituitary cAMP. Either $50 \mu \mathrm{g}$ of $\alpha^{1-24}$ ACTH-Zn, $100 \mu \mathrm{g}$ of dexamethasone phosphate, or saline alone was daily administered to the animals intramuscularly for 3 successive days. The animals were killed by decapitation 24 hours after the last injection. Abbreviations and numbers in brackets in this figure are as in figure 1.

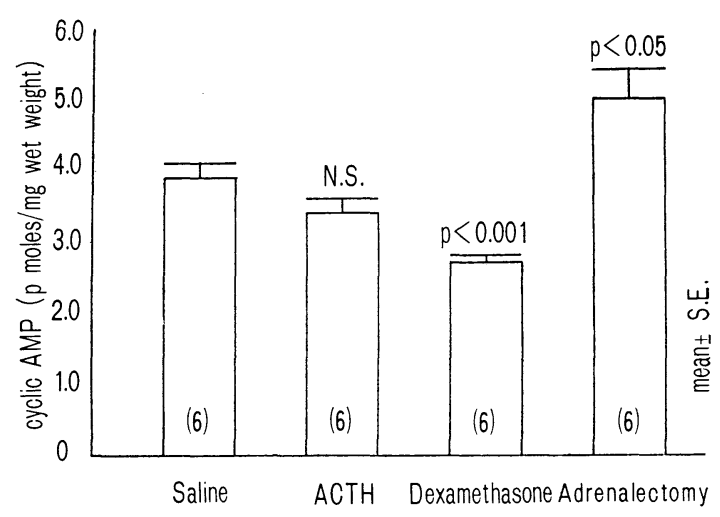

Fig. 3. Effect of adrenalectomy and 7 days' administration of ACTH-Zn or dexamethasone on rat anterior pituitary cAMP. Either $50 \mu \mathrm{g}$ of $\alpha^{1-24}$ ACTH-Zn, $100 \mu \mathrm{g}$ of dexamethasone phosphate or saline alone was daily administered to the animals intramuscularly for 7 successive days. Another animals were subjected to the bilateral adrenalectomy and were decapitated 7 days after the operation. 
The effect of adrenalectomy on the pituitary cAMP content

The pituitary cAMP contents one week after bilateral adrenalectomy were increased significantly either in the total content or in its concentration (Fig. 3).

The effect of the ether-laparotomy stress on the cAMP contents in the pituitary and the adrenal glands

Ten minutes after the stress imposed by ether inhalation and laparotomy, the cAMP contents in both glands increased significantly (Fig. 4, Table 1). In the animals having received intramuscular dexamethasone pretreatment, the ether-laparotomy stress still induced a significant increase in cAMP contents in the anterior pituitary gland (Fig. 4). However, increase of plasma levels of 11-OHCS due to the stress was blocked, although partially, by dexamethasone pretreatment (Fig. 5).

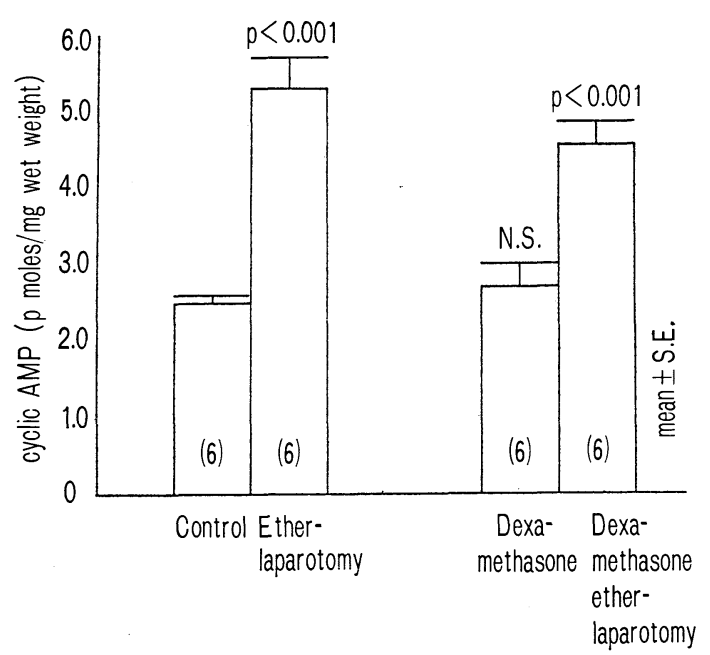

Fig. 4. Effect of ether-laparotomy on cAMP of anterior pituitary from control and dexamethasonetreated rats. The animals were inhalated ether vapor for one minute, immediately followed by laparotomy and were killed by decapitation 10 min. after the ether exposure. Another groups of animals which had been given $100 \mu \mathrm{g}$ of dexamethasone intramuscularly 3 hours prior to the exposure to stress were treated in the same manner.

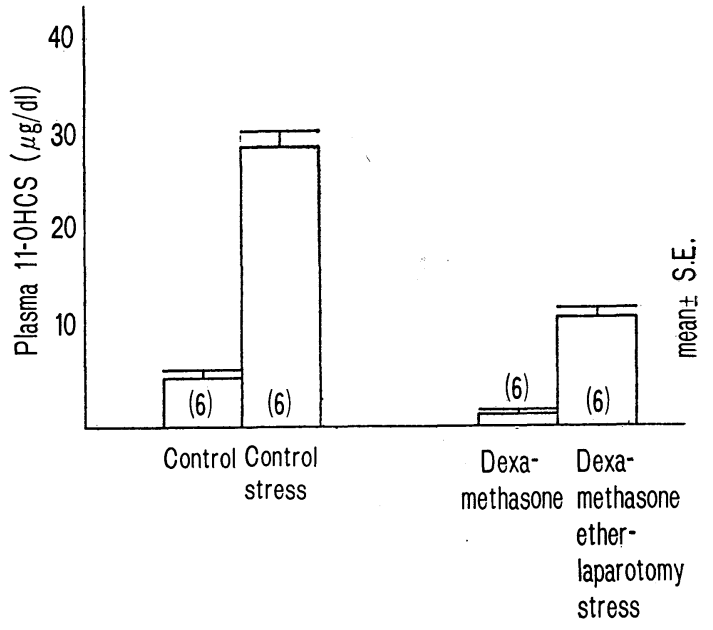

Fig. 5. Effect of ether-laparotomy on plasma 11OHCS of control and dexamethasone-treated rats. See legend in figure 4 for the procedure.

\section{Discussion}

The stimulation of $\mathrm{ACTH}$ release by dibutyryl analogue of cAMP in vivo and in vitro has been reported (Hedge, 1971; Fleisher et al., 1969). Recent report demonstrated an increase in the pituitary cAMP content brought about by neurogenic or anoxic stress (Siegel et al., 1974). It has been shown also that the hypothalamic CRH content increases within minutes after ether-laparotomy stress or neurogenic stress (Vernikos-Danellis, 1963; Hiroshige et al., 1969). An increase of the pituitary cAMP content by ether-laparotomy (Fig. 4), together with the above observations, is consistent with the view that the nucleotide is related to ACTH release and that cAMP is involved in the mediation of the hypothalamo-pituitary-adrenal axis. The increase of the pituitary cAMP levels in adrenalectomized rat (Fig. 3) further indicates an association in vivo between increased ACTH secretion as occurs in adrenalectomized rats and increased cAMP levels.

Dexamethasone pretreatment caused a 
definite inhibition of the increase of plasma 11-OHCS induced by ether-laparotomy, but the effect of such pretreatment on the increase in the pituitary cAMP content was insignificant. It can not be decided whether the slight and insignificant lowering of pituitary cAMP level caused by dexamethasone pretreatment (Fig. 4) is of any meaningful change. Dexamethasone has been shown to inhibit dibutyryl cAMP analogue to induce pituitary ACTH release in vitro (Fleisher et al; 1969), so it seems possible that glucocorticoid may affect the action of such nucleotide acting in the tissue.

The decrease of the pituitary cAMP content after chronic administration of dexamethasone (Fig. 2, 3) might be compatible to the observation that glucocorticoid caused a decrease in the hypothalamic CRH content (Takebe et al., 1971). The decrease in the cAMP content may be corresponded to the decrease of $\mathrm{ACTH}$ release by the chronic administration of the dexamethasone.

The increase of pituitary cAMP content brought about by acute administration of dexamethasone can not be explained at present. It was reported that rats given large doses of the steroid failed to show the pituitary growth hormone depletion normally observed after hypoglycemic stress (Pecile et al., 1966). So it is possible that the steroid also influences cAMP metabolism in the anterior pituitary cells other than corticotrophs. Actually, it has been reported that corticotrophs constitute less than $1 \%$ of the cell population in the anterior pitutary gland of the rat (Nakayama et al., 1969). So it is more probable that the measurable changes of pituitary cAMP reported in the present study are sum of a more generalized response of the cells not limited to the corticotrophs.

Although there remains a possibility that the experimental meneuvers employed in the present study affect functions of pitui- tary cells other than corticotrophs, the results are compatible with the notion that cAMP might be involved in mediating $\mathrm{CRH}$ action in inducing ACTH release from the pituitary.

\section{References}

Bowers, C. Y. (1970). Ann. N. Y. Acad. Sci. 185, 263.

DeMoor, O., O. Steeno, M. Baskin and A. Hendrikx (1960). Acta Endocr. (Kbh.) 33, 297.

Fleischer, N., R. A. Donald and R. W. Butcher (1969). Amer. J. Physiol. 217, 1287.

Hedge, G. A. (1971). Endocrinology 89, 500.

Hiroshige, T., T. Sato, R. Ohta and S. Itoh (1969). Jap. J. Physiol. 19, 866.

Kumon, A., H. Yamamura and Y. Nishizuka (1970). Biochem. Biophy. Res. Commun. 41, 1290.

Nakayama, I., P. A. Nickerson and F. R. Skelton (1969). Lab. Invest. 21, 169.

Oka, H., T. Kaneko, K. Yamashita, S. Suzuki and T. Oda (1973). Endocrinol. Japon. 20, 263.

Pecile, A. and E. E. Muller (1966). J. Endocrinol. 36, 401.

Schofield, J. G. (1967). Nature 215, 1382.

Siegel, R., N. Confronti, S. Feldman and I. Chowers (1974). Neuroendocrinology 14, 24.

Takebe, K., H. Kunita, M. Sakakura, Y. Horiuchi and K. Mashimo (1971). Endocrinology 89, 1014.

Vernikos-Danellis, J. (1963). Endocrinology $72,574$.

Wilber, J., G. T. Peake and R. Utiger (1968). J. Lab. Clin. Med. 72, 1025.

Zor, U., T. Kaneko, H. P. G. Schneider, S. M. McCann, I. P. Lowe, G. Boom, B. Borland and J. B. Field (1969). Proc. Nat. Acad. Sci., Wash. 63, 918. 